www.nature.com/pj

\title{
Significantly improved performance of rubber/silica composites by addition of sorbic acid
}

\author{
Baochun Guo, Feng Chen, Yanda Lei and Weiwei Chen
}

Sorbic acid (SA) was used to improve the performance of styrene-butadiene rubber (SBR)/silica composites by direct blending. The mechanisms for the significantly improved performance were studied by X-ray photoelectron spectroscopy, X-ray diffraction and by the determinations of bound rubber content and crosslink density. The strong interfacial bonding between silica and the rubber matrix resulted from SA-intermediated linkages. Significantly improved dispersion of silica by virtue of the interactions between silica and SA was found. Formation of zinc disorbate during compounding of composites was confirmed. The effects of SA content on vulcanization behavior, morphology, mechanical properties and abrasion loss of composites were studied. Significantly improved mechanical properties of SA-modified SBR/silica composites were demonstrated. Changes in vulcanization behavior, morphology and performance were correlated with the interactions between silica and SA and the largely improved dispersion of silica.

Polymer Journal (2010) 42, 319-326; doi:10.1038/pj.2010.4; published online 17 February 2010

Keywords: interface; SA; SBR; silica; zinc disorbate

\section{INTRODUCTION}

Silica is one of the most important reinforcing fillers in the rubber industry. As a reinforcing filler, silica provides a unique combination of high tear strength, high modulus and fatigue resistance, particularly low rolling resistance and superior wet traction for 'green' tire tread applications. ${ }^{1-5}$ However, numerous hydrophilic silanols exist on the silica surface, resulting in strong filler-filler interactions and poor affinity toward hydrocarbon rubbers, such as styrene-butadiene rubber (SBR). ${ }^{6-8}$ It is well accepted that dispersion and interfacial bonding are two crucial factors in determining the ultimate performance of rubber/silica composites. ${ }^{6}$ Owing to unsatisfactory dispersion and interfacial interactions, the performance of pristine silica-filled SBR compounds in areas such as strength and abrasion resistance hardly meets the requirements for high-performance rubber products. Numerous routes for improving the performance of silicareinforced rubber compounds have been attempted, and some success has been achieved. Incorporation of silanes, especially those containing polysulfides such as Si69 and Si75, during the processing of rubber/silica compounds is the most common practice for improving the overall performance. These modifications establish chemical linkages between the rubber network and the silica surface. ${ }^{9-12}$ Alternatively, grafting techniques also render better dispersion and interfacial bonding in rubber/silica systems. ${ }^{13-17}$ For example, Inoubli et al. ${ }^{14}$ investigated polybutylacrylate (PBA) filled with Stöber silica particles grafted with PBA chains; their small-angle neutron scattering and transmission electron microscopy results showed well-dispersed grafted silica particles in the PBA matrix. Other methods such as thermal treatment ${ }^{18}$ and plasma surface modification of silica ${ }^{19-21}$ were also reported to be effective in tuning the structure and performance of the rubber compounds.

Although remarkable effects have been demonstrated, several problems remain unresolved. First, silanes with polysulfide structures cannot be applied to peroxide-cured rubber compounds. In addition, the grafting method generally involves sophisticated processing, which may result in low controllability of the final performance of materials. As a consequence, we still need the industrially favored process with low fabrication cost and high efficiency of modification.

In this study, SBR compounds reinforced with silica were prepared. Instead of using the above-mentioned modifications, a solid and edible substance, sorbic acid (SA), was adopted as a novel modifier to improve the dispersion of silica in an SBR matrix and the interfacial interaction between the filler and the matrix. Significant modification effects of SA were shown. Compared with conventional methods, the characteristics of this method include largely improved performance, unchanged curing characteristics, environment friendly processing and low fabrication cost. This study aims to characterize the impact of SA on the overall performance of SBR/silica composites and the structural origins for the largely improved performance.

\section{EXPERIMENTAL PROCEDURE}

Materials

SBR, with trademark SBR1502 (styrene content is $23.5 \mathrm{wt} \%$ ), was manufactured by Jilin Chemical Industry Company, Jilin, China. Precipitated silica (ZC 185) was purchased from Nanping Jialian Chemical Group Co. Ltd, Fujian, 
China, and had a specific surface area of $179 \mathrm{~cm}^{2} \mathrm{~g}^{-1}$ (calculated by the Brunauer-Emmett-Teller method on an ASAP 2020 Accelerated Surface Area and Porosimetry System, Micromeritics Instrument Corporation, Norcross, GA, USA). SA with a purity of $98 \%$ was obtained from Ningbo Wanglong Group Co. Ltd, Zhejiang, China. Other additives were of industrial grade and used as received.

\section{Preparation of SBR/silica composites}

SBR and silica were compounded with rubber additives with a two-roll mill at room temperature. The compound was press-cured to a 1-mm-thick sheet at $170^{\circ} \mathrm{C} \times \mathrm{Tc} 90$ and then cut into specimens for measurements. The compositions of the rubber compounds are tabulated in Table 1.

\section{Characterizations}

$X R D$. The X-ray diffraction (XRD) experiments for the uncured rubber compounds and vulcanizates were conducted at room temperature on a Rigaku Dmax/III diffractometer (Rigaku Corporation, Tokyo, Japan) using $\mathrm{CuK} \alpha$ radiation $(\lambda=1.54 \AA)$. The accelerating voltage and current were $40 \mathrm{kV}$ and $30 \mathrm{~mA}$, respectively. Samples were scanned from 2 to $50^{\circ}$ with a step length of 0.02 .

XPS. A model compound was prepared to explore the possible interactions between silica and SA. The blend of silica/SA/dicumyl peroxide (DCP) (weight ratio of 20:5:0.5) was premixed and treated at $170{ }^{\circ} \mathrm{C}$ for $30 \mathrm{~min}$ in a sealed vessel and then used for X-ray photoelectron spectroscopy (XPS) analysis. XPS spectra of silica (dried at $80^{\circ} \mathrm{C}$ for $3 \mathrm{~h}$ ) and of the above-mentioned silica/SA/DCP compound were recorded using an X-ray Photoelectron Spectrometer (Kratos Axis Ultra DLD, Kratos Analytical Inc., Chestnut Ridge, NY, USA) with an aluminum (mono) $\mathrm{K} \alpha$ source $(1486.6 \mathrm{eV})$. The aluminum $\mathrm{K} \alpha$ source was operated at $15 \mathrm{kV}$ and $10 \mathrm{~mA}$. For both samples, a high-resolution survey (pass energy $=48 \mathrm{eV}$ ) was performed in the spectral region relating to the silicon atom. All core-level spectra were referenced to the $\mathrm{C} 1 \mathrm{~s}$ neutral carbon peak at $285.0 \mathrm{eV}$.

Determination of bound rubber and crosslink density. Bound rubber corresponds to the fraction of rubber bound by filler. The method proposed by the reported procedure was used to determine the bound rubber content in different rubber compounds. ${ }^{22,23}$ Uncured rubber compounds were kept for a week at room temperature for the determination of bound rubber. All samples (about $2 \mathrm{~g}$ each) were cut into small pieces and placed in a steel wire basket. The basket was then suspended in a mixture of isopropanol and toluene for 3 days (solvent changed every day) and with acetone for 1 day at room temperature and then dried in a vacuum oven for $24 \mathrm{~h}$ at $60^{\circ} \mathrm{C}$. The weight of samples before and after extraction was measured, and the bound rubber contents were calculated.

Crosslink density was determined by the equilibrium swelling method. The value was classified into three types: covalent bonded, ionic bonded and total crosslink density (covalent plus ionic bonded). Samples were swollen in toluene at room temperature for $72 \mathrm{~h}$ and then removed from the solvent, after which surface toluene was blotted off quickly with tissue paper. The samples were immediately weighed on an analytical balance, dried in a vacuum oven for $36 \mathrm{~h}$ at $80^{\circ} \mathrm{C}$ to remove all solvent and reweighed. The volume fraction of SBR in the swollen gel, $\mathrm{Vr}$, was calculated by the following equation: ${ }^{24}$

$$
\mathrm{Vr}=\frac{m_{0} \times \phi \times(1-\alpha) / \rho_{\mathrm{r}}}{m_{0} \times \phi \times(1-\alpha) / \rho_{\mathrm{r}}+\left(m_{1}-m_{2}\right) / \rho_{\mathrm{s}}},
$$

where $m_{0}$ is the sample mass before swelling; $m_{1}$ and $m_{2}$ are the sample masses before and after drying, respectively; $\phi$ is the mass fraction of rubber in the

Table 1 Composition of SBR/silica composites ${ }^{a}$

\begin{tabular}{lrrrrrr}
\hline Sample code & SBR & SBR 2A & SBR 5A & SBR 9A & SBR 12A & SBR 15A \\
\hline SBR & 100 & 100 & 100 & 100 & 100 & 100 \\
Silica & 40 & 40 & 40 & 40 & 40 & 40 \\
SA & 0 & 2 & 5 & 9 & 12 & 15
\end{tabular}

Abbreviations: SA, sorbic acid; SBR, styrene-butadiene rubber.

aRubber intergradients: zinc oxide, $5 \mathrm{phr}$; stearic acid, $1 \mathrm{phr}$; dicumyl peroxide (DCP), $1.0 \mathrm{phr}$ 2-mercapto benzimidazole (MB), $1.5 \mathrm{phr}$. vulcanizate; $\alpha$ is the mass loss of the gum SBR vulcanizate during swelling; and $\rho_{\mathrm{r}}$ and $\rho_{\mathrm{s}}$ are the rubber and solvent density, respectively.

The elastically active network chain density, Ve, which was used to represent the whole crosslink density, was then calculated by the well-known FloryRehner equation: ${ }^{25}$

$$
\mathrm{Ve}=-\frac{\ln (1-\mathrm{Vr})+\mathrm{Vr}+\chi \mathrm{Vr}^{2}}{\mathrm{Vs}\left(\mathrm{Vr}^{1 / 3}-\mathrm{Vr} / 2\right)}
$$

where $\mathrm{Vr}$ is the volume fraction of the polymer in the vulcanizate swollen to equilibrium and $\mathrm{Vs}$ is the solvent molar volume $\left(107 \mathrm{~mol} \mathrm{~cm}^{-3}\right.$ for toluene). $\chi$ is the SBR-toluene interaction parameter and is taken as 0.0653 , calculated according to reference. ${ }^{26}$

As mentioned above, vulcanizates contained both covalent and ionic crosslinks; hence, it is important to distinguish ionic crosslink density from covalent crosslink density. To determine covalent crosslink density, samples were swollen again in a mixture of toluene and dichloroacetic acid (90:10 in mass) for $120 \mathrm{~h}$ to destroy ionic crosslinks, swollen in toluene for $72 \mathrm{~h}$ and weighed, and then vacuum dried and reweighed. $\mathrm{Vr}_{1}$, calculated by Equation (1), represents the extent of swelling after destroying ionic crosslinks. $\mathrm{Ve}_{1}$, calculated by Equation (2), represents the covalent crosslink density. $\mathrm{Ve}_{2}$, calculated by subtracting $\mathrm{Ve}_{1}$ from Ve, represents the ionic crosslink density.

Dynamic mechanical analysis. This analysis was conducted with an EPLEXOR $500 \mathrm{~N}$ DMTS instrument (GABO, Ahlden, Germany) under a tension mode at a frequency of $1 \mathrm{~Hz}$ with a dynamic strain of $0.5 \%$ from -100 to $150{ }^{\circ} \mathrm{C}$ at $3{ }^{\circ} \mathrm{C} \min ^{-1}$

Morphological observations. The tensile fractured surfaces were plated with a thin layer of gold before any observations. Scanning electron microscope (SEM) observations were then carried out using a 1530 VP SEM machine (LEO, Oberkochen, Germany).

Mechanical properties and abrasion resistance. Tensile tests were performed following ISO standard $37-2005$ at $25^{\circ} \mathrm{C}$. Tensile strength, modulus and elongation at break were measured using a U-CAN UT-2060 instrument (U-CAN Dynatex Inc, Nantou City, Taiwan).

The abrasion property of composites was evaluated by determining the abrasion volume per $1.61 \mathrm{~km}$ using an Akron abrasion tester.

\section{RESULTS AND DISCUSSION}

\section{In situ formation of ZDS and interactions between SA and silica} The in situ formation of zinc disorbate (ZDS) from zinc oxide and SA has been reported in our previous study. ${ }^{27}$ To verify the in situ formation of ZDS in this system, XRD measurements of SBR/silica rubber compounds were determined. Figure 1 represents the XRD

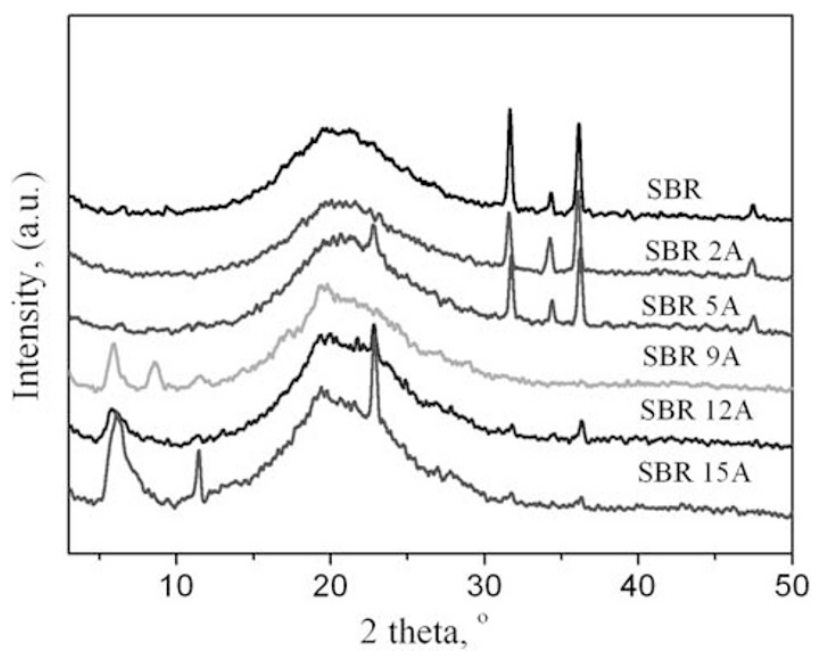

Figure 1 XRD patterns of uncured SBR/silica compounds. 
patterns of uncured rubber compounds with a variable SA content. As shown, the intensity of peaks at 31.6 and $36.1^{\circ}$, characterizing the (100) and (101) diffractions of $\mathrm{ZnO}^{28}$ respectively, consistently decrease with SA loading to eventually disappear at 9 phr of SA. It can be noted that with the decrease in $\mathrm{ZnO}$, the intensity of the peak at $6.1^{\circ}$, which characterizes the diffraction of ZDS, ${ }^{29}$ consistently increases with SA loading. The presence of diffraction at $6.1^{\circ}$ confirms the in situ formation of ZDS in this system. Except for this observation, two peaks at 11.4 and $27.8^{\circ}$, which are assigned to the diffractions of SA, appear at an SA content of $15 \mathrm{phr}$. This result may be due to the residual SA from the reaction between $\mathrm{ZnO}$ and SA. $\mathrm{ZnO}$ reacts with SA to form ZDS at a theoretical molar ratio of 0.5 . When the SA content is beyond $12 \mathrm{phr}$, SA is present in excess, yielding diffractions at 11.4 and $27.8^{\circ}$.

Figure 2 shows the XRD patterns of SBR/silica vulcanizates. No visible peak at $6.1^{\circ}$ is observed for any of the samples, suggesting a

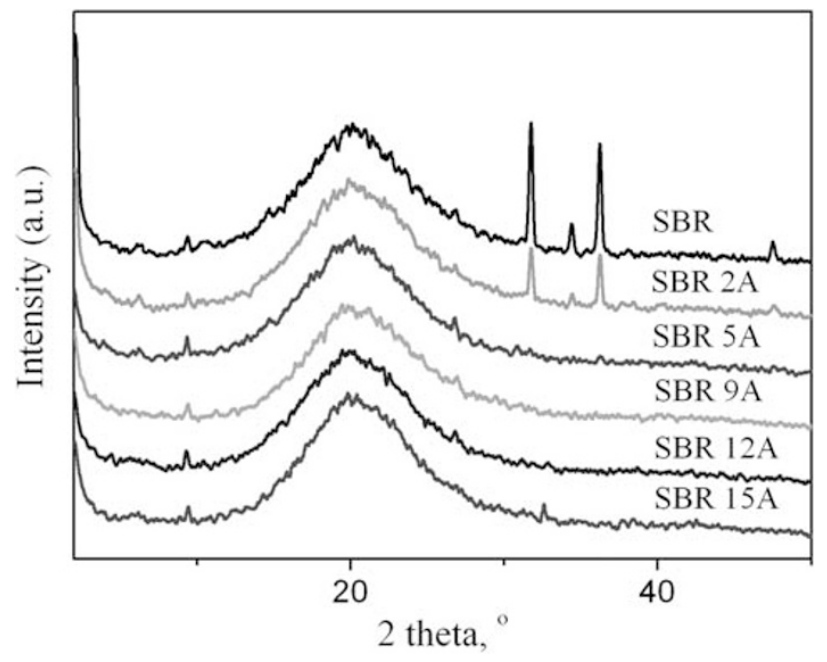

Figure 2 XRD patterns of SBR/silica vulcanizates. complete conversion of ZDS to polymerized ZDS during vulcanization. Under a radical mechanism, ZDS undergoes crosslinking to form thermosetting particles. The crosslinked ZDS is actually a thermosetting ionomer, which is illustrated in Scheme 1. At the same time, the disappearance of peaks at 11.4 and $27.8^{\circ}$ also indicates that the polymerization of SA takes place during vulcanization. On heating, free radicals are generated, and the ZDS, excess SA and SBR are cocured into a network structure. The co-curing of SBR and ZDS leads to the formation of ionic crosslinks between the SBR chains. The formation of ionic crosslinks is verified in Figure 3, in which the dependence of crosslink densities on composition is depicted. One can see that the ionic crosslink density $\left(\mathrm{Ve}_{2}\right)$ is slightly increased with SA loading. However, the increase in $\mathrm{Ve}_{2}$ cannot compensate for the decrease in covalent crosslink density $\left(\mathrm{Ve}_{1}\right)$, which is caused by the formation of linear poly(SA); consequently, the total crosslink density (Ve, covalent plus ionic bonded) decreases. It is also clear that the

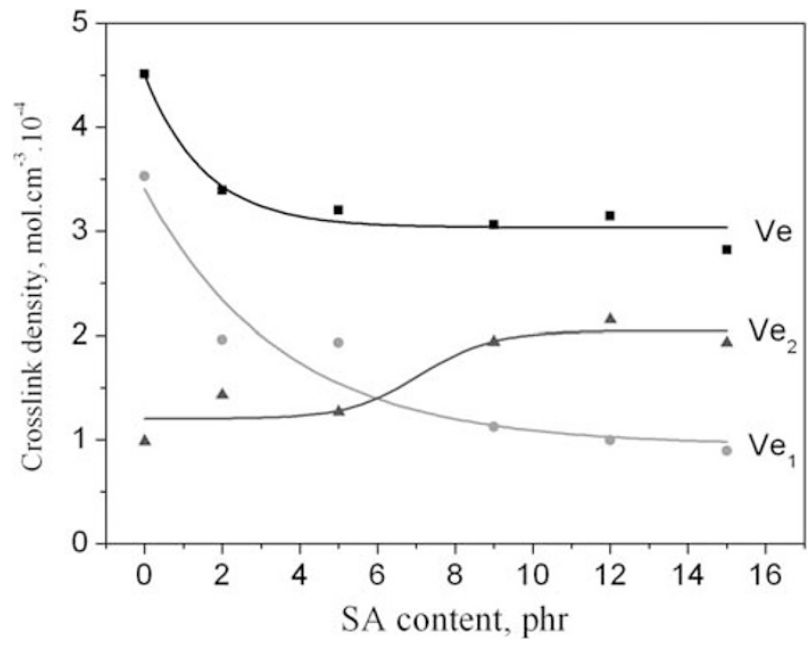

Figure 3 Effect of SA content on crosslink density.

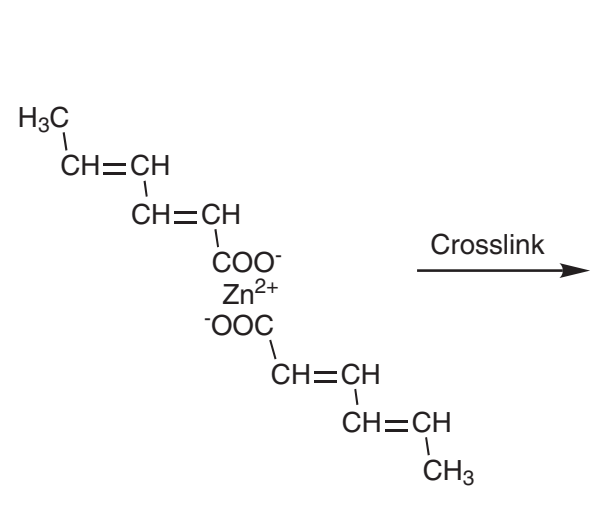

Zinc disorbate (ZDS)

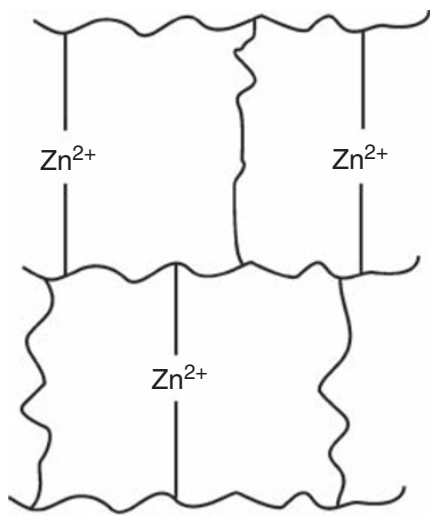

Poly (ZDS)<smiles>[X][O+]C(C=CC(C)C(C)(C)C)C([X])(C)C</smiles>

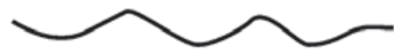

Scheme 1 Schematic illustration of the structure of polymerized ZDS. 
ionic crosslink density is below $2 \times 10^{-4} \mathrm{~mol} \mathrm{~cm}^{-3}$ for all samples, suggesting the limited formation of ZDS in the present system.

When SA is incorporated into the SBR/silica system, on the one hand, SA is grafted onto SBR chains through radical copolymerization; on the other hand, because of the abundant surface silanols on silica, SA can attach to silica through hydrogen bonding. It is well known that the formation of hydrogen bonding leads to variation in the chemical environment, which can be characterized by the variation in the bonding energy of related atoms through an XPS survey. ${ }^{30-32}$ As can be seen in Figure 4, the bonding energy of the silicon atom, which connects to the oxygen atom in the hydrogen bond, is decreased from 103.6 to $103 \mathrm{eV}$, indicating the formation of hydrogen bonding between silica and polymerized SA. As a consequence, the interface between SBR and silica may also be strengthened by silica by means of grafting and hydrogen bonding mechanisms.

Many studies have shown that the addition of silica into a rubber matrix can lead to the formation of a rubber layer in the vicinity of the filler surface, known as bound rubber., ${ }^{5,22,23}$ The mechanism and factors affecting the formation of bound rubber are very complicated. $^{33,34}$ Figure 5 shows the effect of SA content on the bound rubber content of rubber compounds. It is clear that the bound rubber content increases notably with the incorporation of SA, suggesting a remarkably improved interface interaction between silica and the SBR matrix. It is well known that silica tends to agglomerate and has limited interaction with the nonpolar rubber matrix. Thus, the bound rubber content of the control sample is relatively low. Once SA is added into the system, the carboxyl group on the SA molecule bonds to silica through hydrogen bonding. The chemical bonds between the rubber matrix and silica through SA intermediate linkage enhance the bound rubber formation.

\section{Curing characteristics of SBR/silica compounds}

The vulcanization curves for SBR/silica compounds with varying contents of SA are shown in Figure 6. As can be seen, the maximum torque of the compound decreases with increasing SA loading. Owing to the strong filler-filler interactions between silica, it agglomerates in the rubber matrix in the absence of SA, resulting in higher effective filler volumes. ${ }^{35}$ Once SA is incorporated, the dispersion of silica is largely improved and the effective filler volume consistently decreases. In addition, with the increase in SA content, the content of the linear structure poly(SA) formed during vulcanization also consistently increases, leading to a decrease in crosslink density. As a consequence,

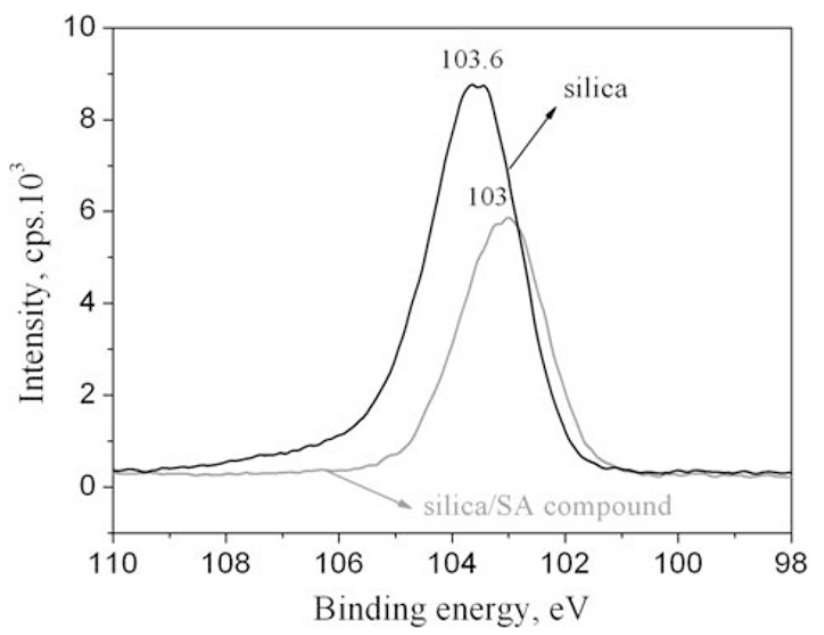

Figure 4 XPS results of silica and silica/SA model compounds. the maximum torque decreases with SA content. Figure 7 summarizes the scorch time (Ts2) and vulcanization time (Tc90) of rubber compounds. As shown, Ts2 is almost independent of SA loading. Tc90 first increases with the incorporation of SA, then decreases when the SA content is beyond 5 phr. DCP can initiate the crosslinking of

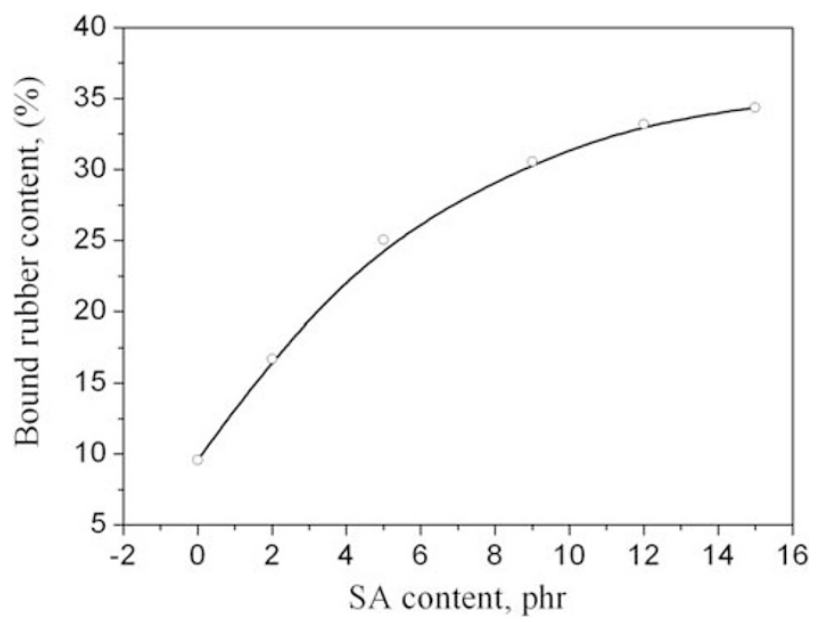

Figure 5 Effect of SA content on the bound rubber content of rubber compounds.

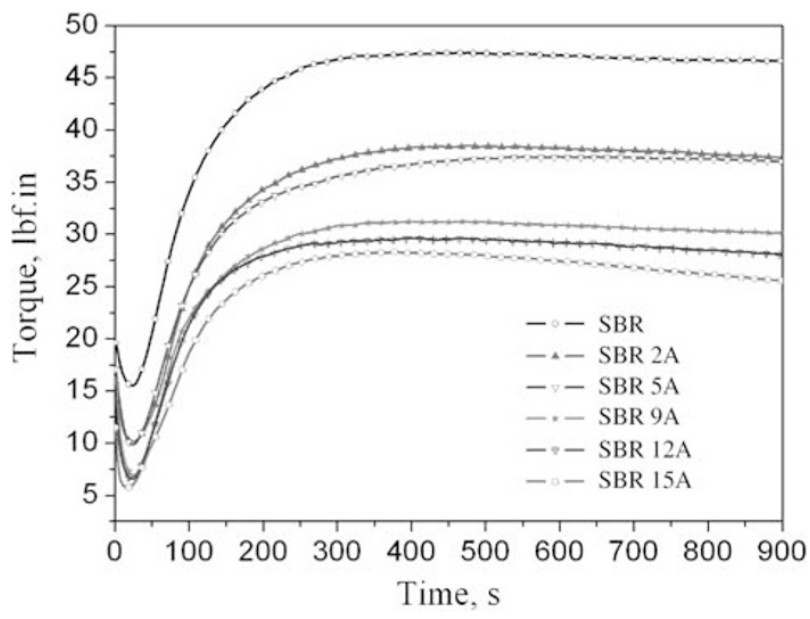

Figure 6 Vulcanization curves of SBR/silica compounds.

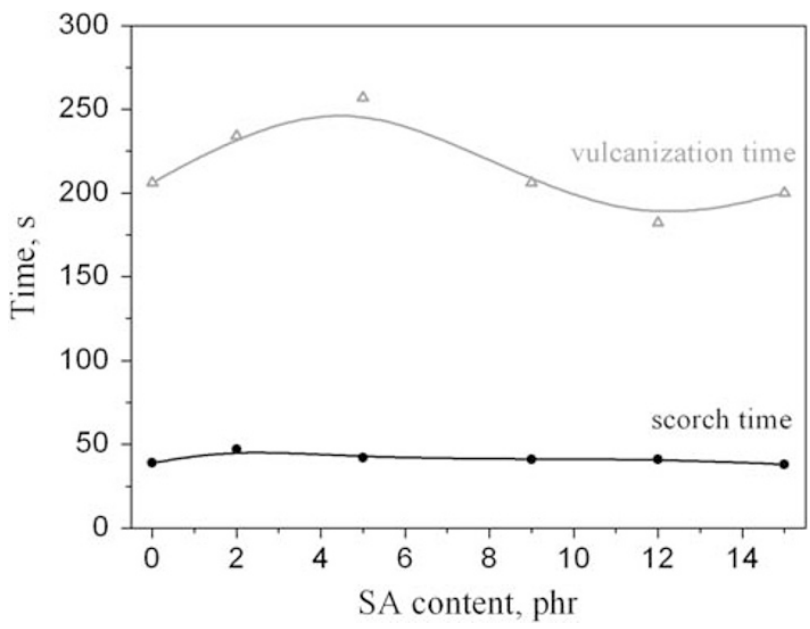

Figure 7 Vulcanization and scorch time of SBR/silica compounds. 
SBR, as well as the polymerization of SA or ZDS. When SA is incorporated, part of the DCP is consumed by SA or ZDS before the vulcanization of SBR. Consequently, the vulcanization time is slightly increased. As the SA content is further increased, the interfacial bonding between SBR and silica is substantially increased. The increased interfacial bonding compensates for the above-mentioned

a

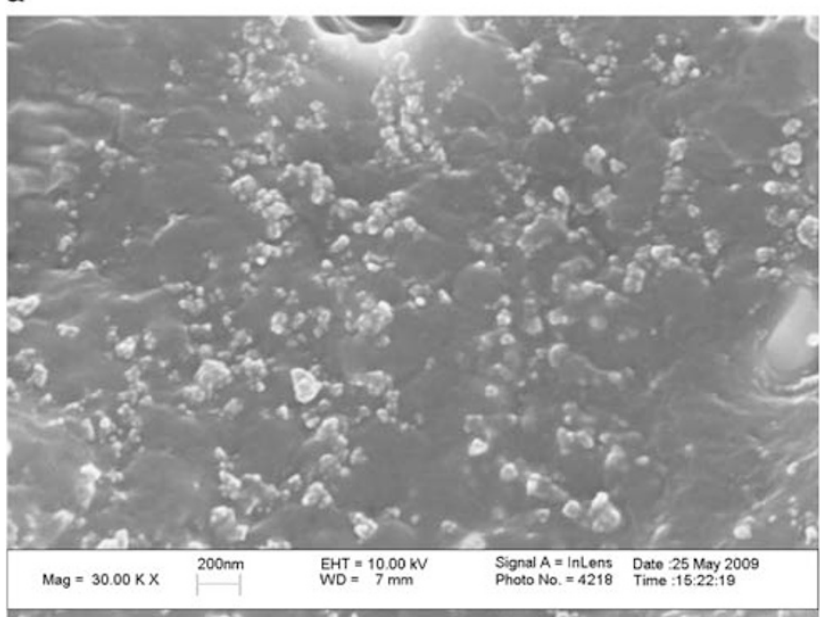

b

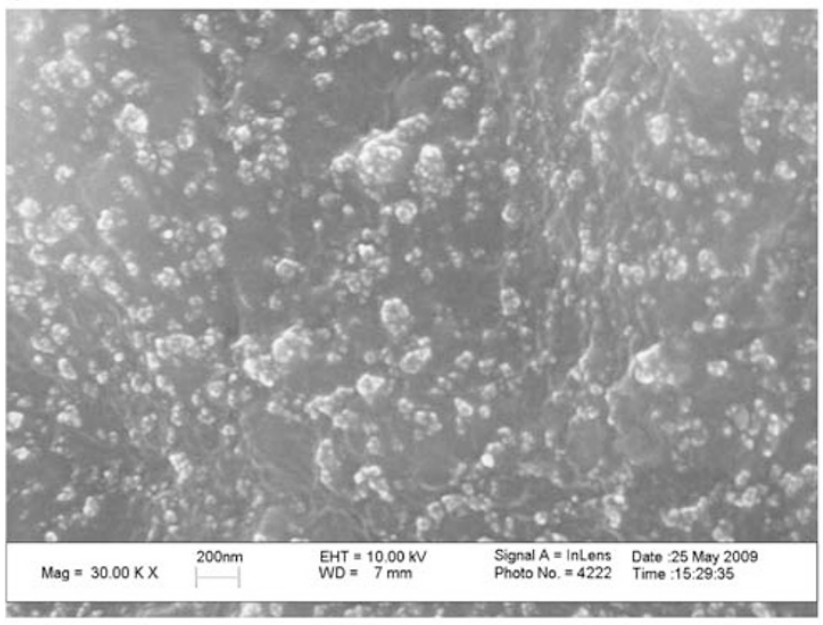

C

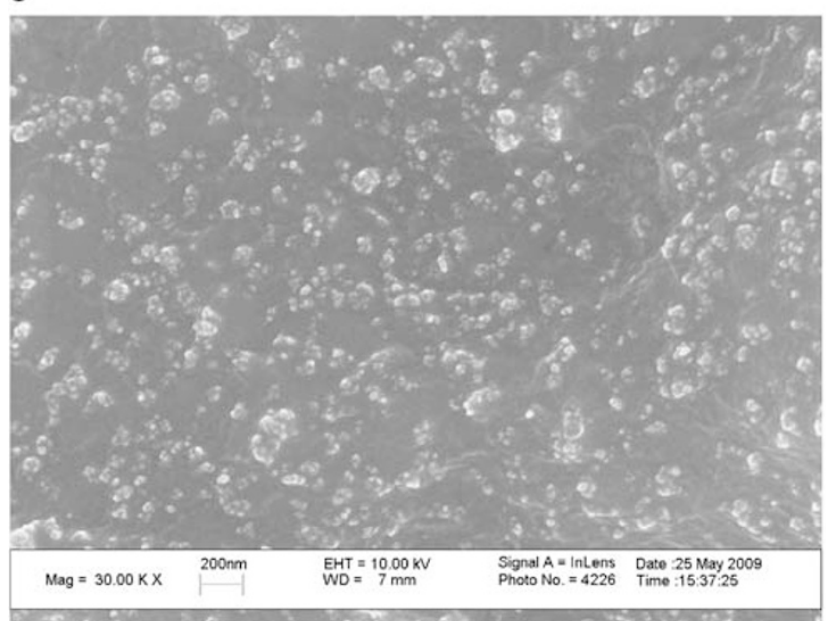

delay in vulcanization, resulting in a basically unchanged vulcanization time compared with that of the control sample.

\section{Morphology and performances of SBR/silica composites}

Figure 8 presents a comparison of the SEM photos of SBR/silica composites. It can be seen that agglomerates of silica with different

d

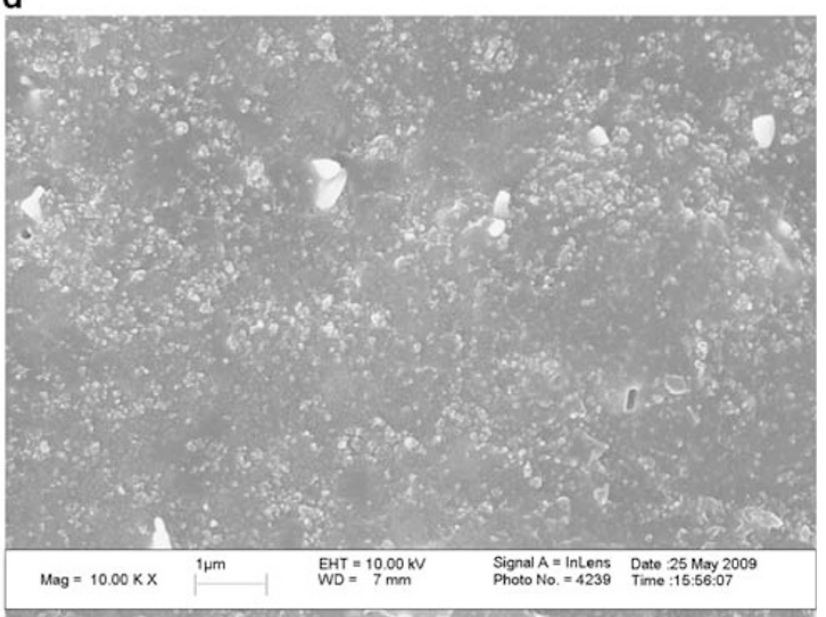

e

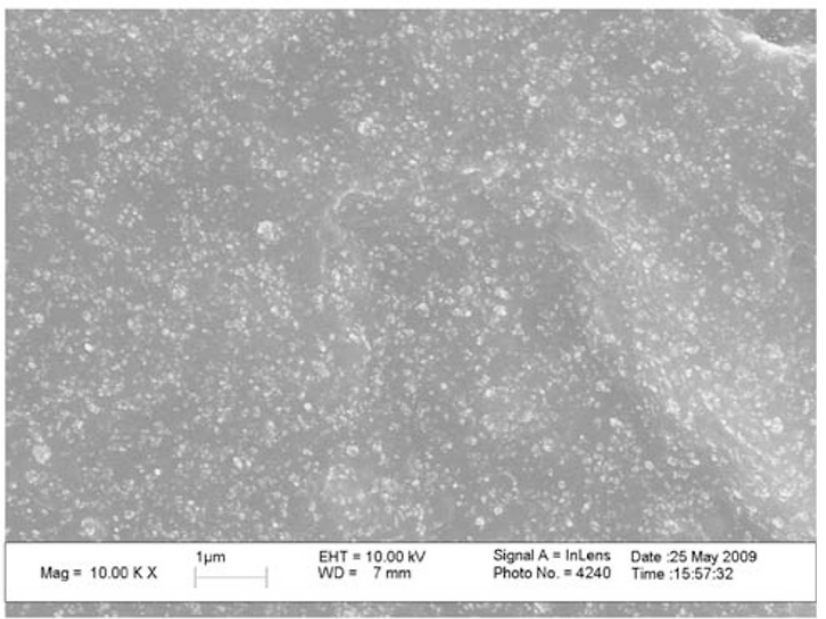

f

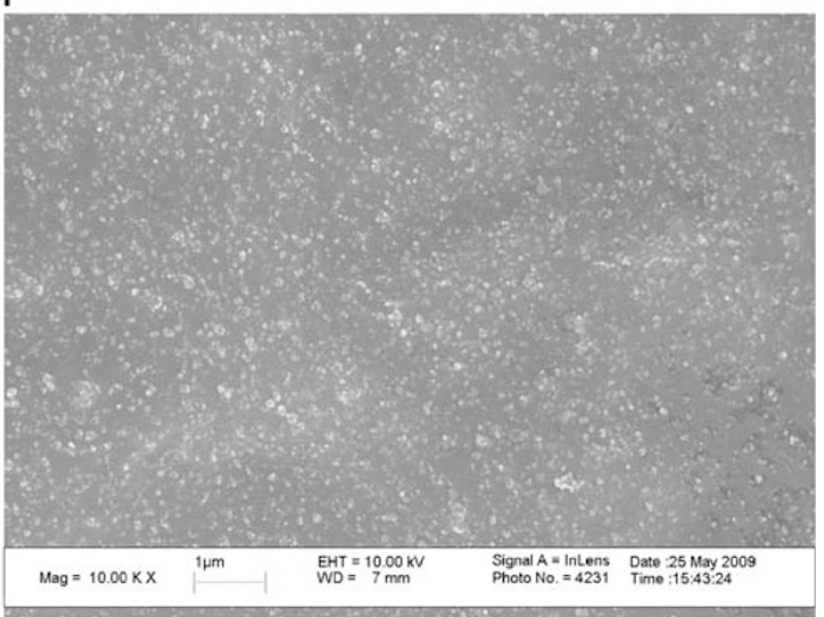

Figure 8 Morphology of SBR/silica composites at different magnifications. (a, d) SEM of SBR; (b, e) SEM of SBR 5A; (c, f) SEM of SBR 9A. 
sizes are observed for the control sample. The system containing SA, however, possesses a much finer dispersion of silica, which is better with a higher content of SA. The remarkable effect of SA on promoting the dispersion of silica is attributed to the interfacial hydrogen bonding between SA and silica.

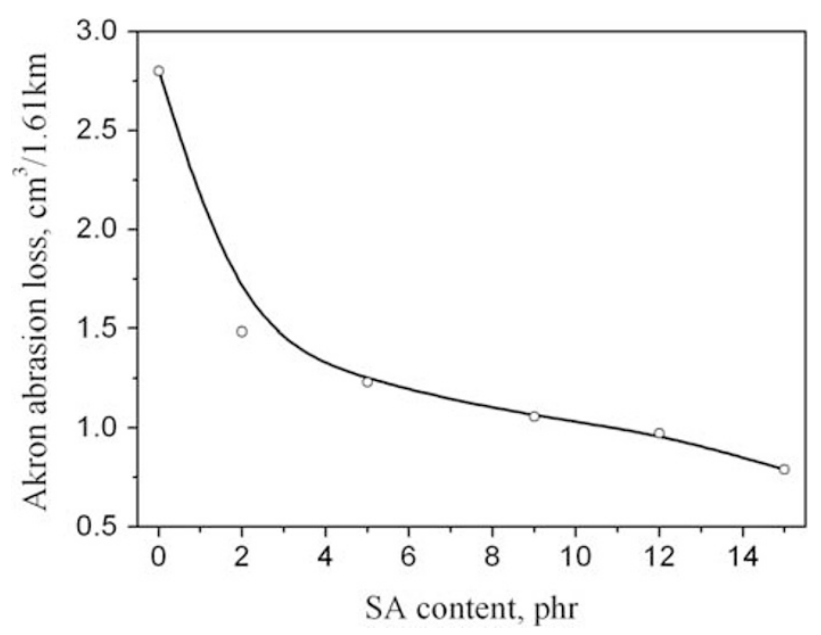

Figure 9 Abrasion loss of SBR/silica composites with different SA contents.
Silica has been used to improve wet traction and lower rolling resistance of rubber products in tire applications, although the abrasion resistance of silica-filled products is generally inferior to that of carbon black-filled counterparts. ${ }^{36,37}$ The effect of SA content on the abrasion resistance of SBR/silica composites is revealed in Figure 9. As shown, the Akron abrasion loss of composites decreases sharply with increasing SA loading. The significant improvement in abrasion property is due to the enhanced interfacial adhesion between SBR and silica.

The dynamic mechanical properties of filled polymer were investigated to study the interfacial region of the composite. Figure 10 depicts the dynamic mechanical analysis curves of the SBR/silica composite without SA and the two composites with $5 \mathrm{phr}$ and 15 phr SA. As can be seen in Figure 10a, when 15 phr SA is used, the storage moduli $\left(\mathrm{E}^{\prime}\right)$ at temperatures of -20 to $50^{\circ} \mathrm{C}$ are substantially higher than those of the control sample. This observation may be attributed to ionic aggregate formation in the composite, which collapses at higher temperatures. ${ }^{38}$ When 5 phr of SA is included, the $\mathrm{E}^{\prime}$ values of the sample at temperatures of -20 to $50{ }^{\circ} \mathrm{C}$ are almost unchanged because of the limited content of ionic aggregates at such low SA loading. The effect of SA on loss moduli $\left(\mathrm{E}^{\prime \prime}\right)$ is shown in Figure $10 \mathrm{~b}$, in which we can see that the value of $\mathrm{E}^{\prime \prime}$ above $0{ }^{\circ} \mathrm{C}$ is significantly increased when sufficient SA (15 phr) is included. Under dynamic strain, the dissociated ionic domains at higher temperature (above $0{ }^{\circ} \mathrm{C}$ ) may cause substantially increased loss. Because a higher
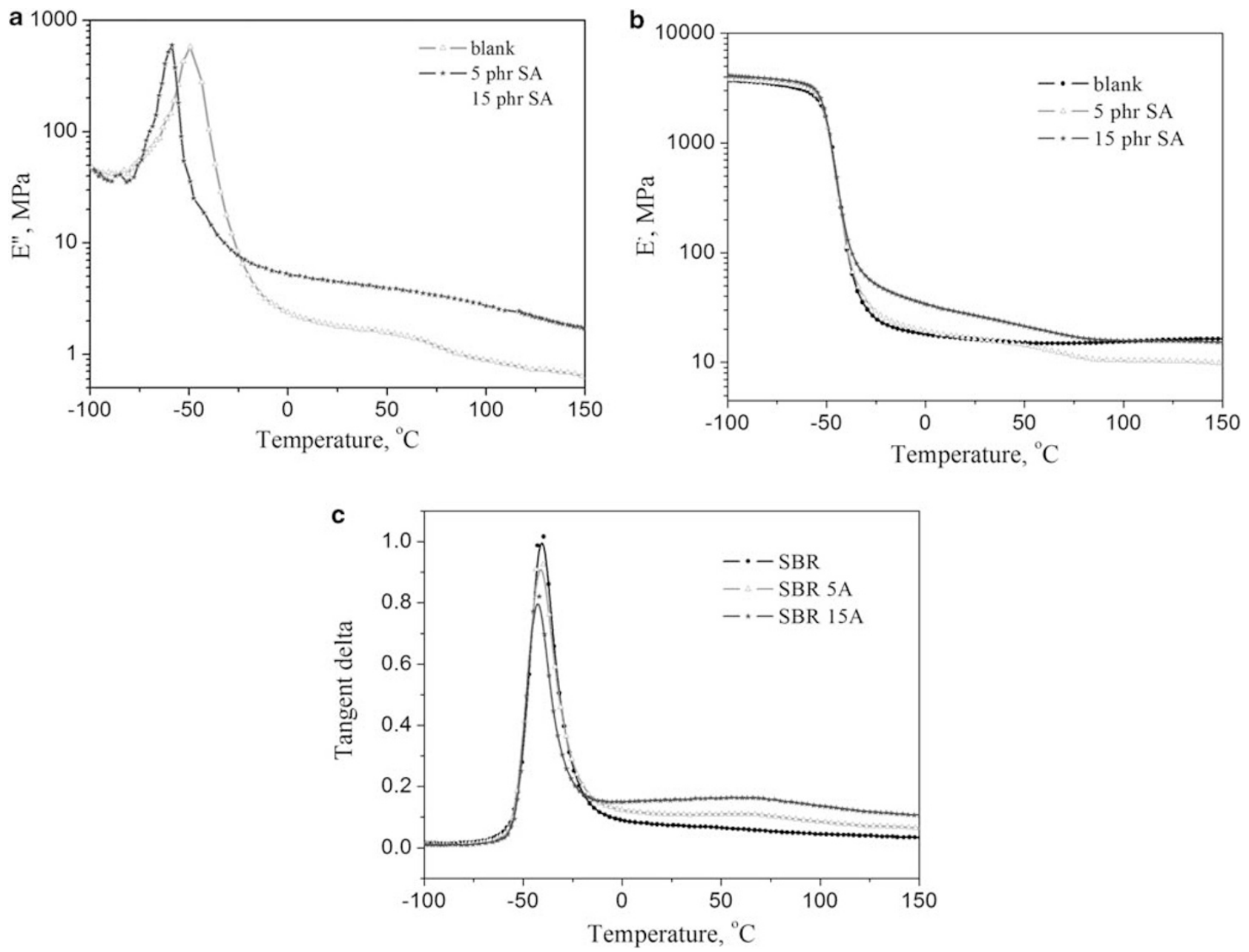

Figure 10 Experimental DMA curves of SBR/silica composites (a) storage modulus; (b) loss modulus; (c) tangent delta 


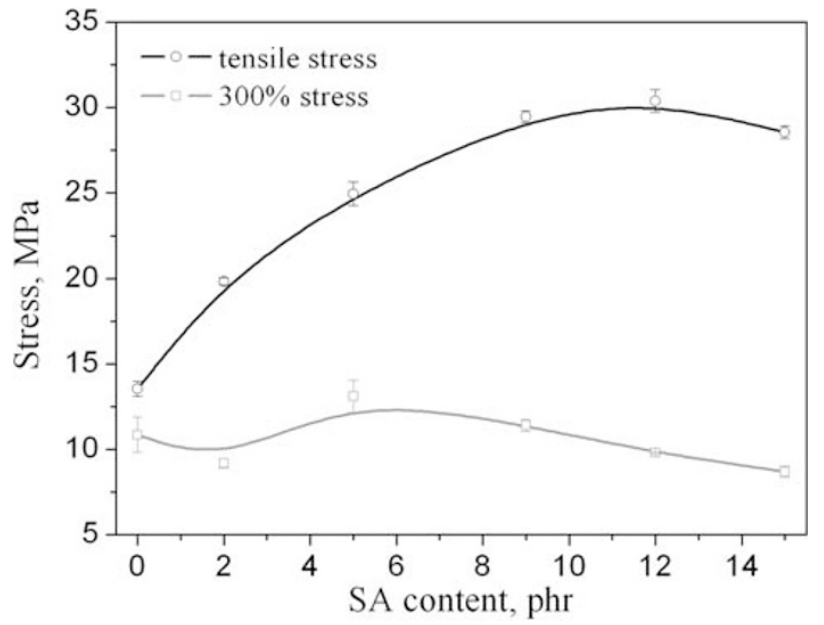

Figure 11 Effect of $S A$ content on tensile properties of SBR/silica composites.

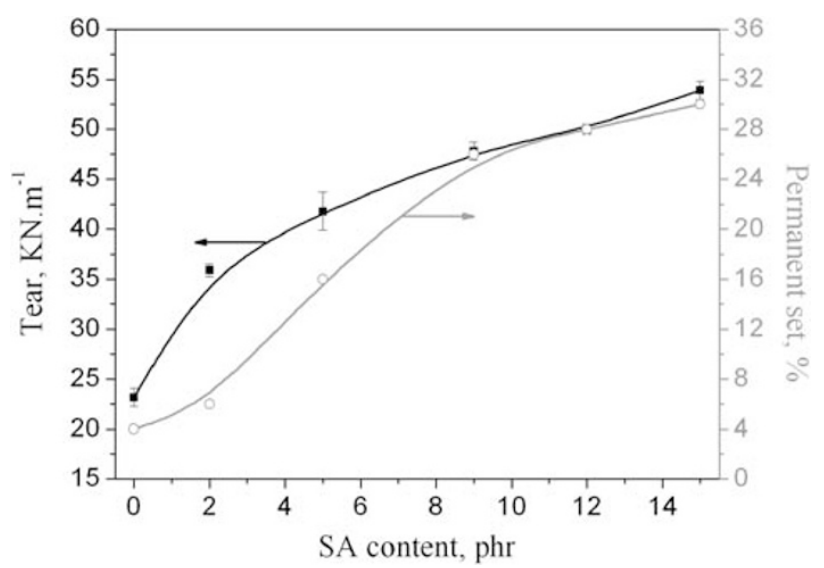

Figure 12 Effect of SA content on tear properties and permanent set of the SBR/silica composites.

content of SA leads to a higher content of the ionic domain, the $E^{\prime \prime}$ values of the sample with $15 \mathrm{phr}$ SA are higher than those of the sample with $5 \mathrm{phr}$ SA. It is obvious in Figure 10c that the tangent delta at the glass transition temperature $(\mathrm{Tg})$ decreases with the incorporation of SA. When SA is added to the system, the bound rubber content increases, and mobility of the rubber chains is reduced substantially; hence, the tangent delta value in the transition region decreases. The broad peaks for samples SBR $5 \mathrm{~A}$ and SBR $15 \mathrm{~A}$ around $50-100^{\circ} \mathrm{C}$ could be caused by the ionic segments exchanging counter cations between one site and another. ${ }^{38}$

Figures 11 and 12 depict the mechanical properties of SBR/silica composites with different SA contents. It is clear that the tensile strength and tear properties of composites are enhanced significantly. When the SA content is $12 \mathrm{phr}$, both tensile strength and tear strength are doubled. However, when excess SA is included, the dispersion state of silica may not be significantly changed and linear poly(SA) may result. Consequently, further incorporation of SA deteriorates tensile strength and modulus and leads to the increased permanent set of composites. Figure 13 contains the stress-strain curves for SBR/silica composites. One can see that higher loading of SA effectively increases the elongation at break. When the content of SA exceeds the quantity of SA that can completely react with $\mathrm{ZnO}$, the residual SA is crosslinked into a polymer with a linear structure, which leads to a high

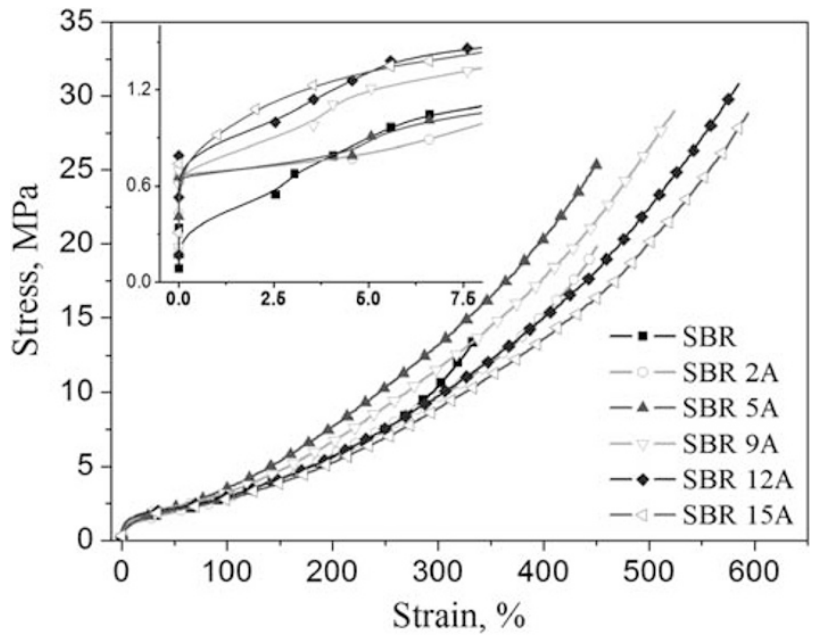

Figure 13 Effect of SA content on the stress-strain curve of SBR/silica composites.

elongation at break. The magnified stress-strain curves at small strain for the determination of Young's modulus are inserted in Figure 13. Clearly, when SA is incorporated, the Young's modulus of the composite (as indicated by the slope) is lower than that of the control. In addition, the Young's modulus of the included SA sample increases with the content of SA. The Young's modulus of the vulcanizate reflects the ideal elasticity of the rubber network. ${ }^{39}$ When SA is used, it can be grafted onto SBR chains, leading to a looser network with lowered elasticity. In addition to the modifications of the rubber network, another effect of SA is a much-improved silica dispersion, which could compensate for the decrease in elasticity. Consequently, when SA content increased, Young's modulus gradually increased.

The significantly enhanced mechanical properties and decreased abrasion loss can mainly be explained by the following two arguments. First, the interfacial bonding between silica and the rubber matrix is significantly increased because of SA-intermediated linkages. SA bonds SBR and silica through a grafting copolymerization/hydrogen bonding mechanism. Second, the significantly improved dispersion of silica (to be substantiated below) by virtue of the interactions between silica and SA largely increases the interfacial volume between silica and the matrix (as indicated by the bound rubber results), which are also important in improving performance. An overloading of SA leads to a high retention of linear poly(SA) in the vulcanized composite, and consequently, the composite with a high content of SA shows a lower modulus and higher permanent set, which are undesirable behaviors for rubber.

\section{CONCLUSIONS}

SA was used to improve the performance of SBR/silica composites by direct blending. The strong interfacial interaction between silica and the rubber matrix resulted from SA-intermediated linkages. SA bonded SBR and silica through a grafting copolymerization/hydrogen bonding mechanism. Significantly improved dispersion of silica by virtue of the interactions between silica and SA was found. Formation of ZDS during the compounding of composites was verified. Significantly improved mechanical properties and decreased abrasion loss of SA-modified SBR/silica composites were demonstrated. The changes in vulcanization behavior, mechanical properties and morphology were correlated with the interactions between silica and SA and the significantly improved dispersion of silica. 


\section{ACKNOWLEDGEMENTS}

The authors appreciate the financial support of the National Natural Science Foundation of China (50873035 and 50933001).

1 Ou, Y. C., Yu, Z. Z., Vidal, A. \& Donnet, J. B. Effects of alkylation of silicas on interfacial interaction and molecular motions between silicas and rubbers. J. Appl. Polym. Sci. 59, 1321-1328 (1996).

2 Wagner, M. P. Reinforcing silicas and silicates. Rubber Chem. Technol. 49, 703-774 (1976).

3 Waddell, W. H., O'Haver, J. H., Evans, L. R. \& Harwell, J. H. Organic polymer-surface modified precipitated silica. J. Appl. Polym. Sci. 55, 1627-1641 (1995).

4 Luginsland, H. D., Frohlich, J. \& Wehmeier, A. Influence of different silanes on the reinforcement of silica-filled rubber compounds. Rubber Chem. Technol. 75, 563-579 (2002).

5 Choi, S. S. Filler-polymer interactions in both silica and carbon black filled styrenebutadiene rubber compounds. J. Polym. Sci. Part B Polym. Phys. 39, 439-445 (2001).

6 Brinke, J. O., Litvinov, V. M., Wijnhoven, J.E.G.J. \& Noordermeer, J. W. M. Interactions of stöber silica with natural rubber under the influence of coupling agents, studied by ${ }^{1}$ H NMR T2 relaxation analysis. Macromolecules 35, 10026-10037 (2002).

7 Choi, S. S. Influence of the silica content on rheological behaviour and cure characteristics of silica-filled styrene-butadiene rubber compounds. Polym. Int. 50, 524-530 (2001).

8 Hashim, A. S., Azahari, B., Ikeda, Y. \& Kohjiya, S. The effect of bis(3-triethoxysilylpropyl) tetrasulfide on silica reinforcement of styrene-butadiene rubber. Rubber Chem. Technol. 71, 289-299 (1998).

9 Ansarifar, A., Wang, L., Ellis, R. J., Kirtley, S. P. \& Riyazuddin, N. Enhancing the mechanical properties of styrene-butadiene rubber by optimizing the chemical bonding between silanized silica nanofiller and the rubber. J. Appl. Polym. Sci. 105, 322-332 (2007).

10 Sae-oui, P., Sirisinha, C., Thepsuwan, U. \& Hatthapanit, K. Roles of silane coupling agents on properties of silica-filled polychloroprene. Europ. Polym. J. 42, 479-486 (2006).

11 Poh, B. T. \& Ng, C. C. Effect of silane coupling agents on the mooney scorch time of silica-filled natural rubber compound. Europ. Polym. J. 34, 975-979 (1998).

12 Yan, H. X., Tian, G. H., Sun, K., Zhang, Y. \& Zhang, Y. X. Effect of silane coupling agent on the polymer-filler interaction and mechanical properties of silica-filled NR. J. Polym. Sci. Part B Polym. Phys. 43, 573-584 (2005).

13 Berriot, J., Montes, H., Martin, F., Mauger, M., Pyckhout, H. W., Meier, G. \& Frielinghaus, H. Reinforcement of model filled elastomers: synthesis and characterization of the dispersion state by SANS measurements. Polymer 44, 49094919 (2003).

14 Inoubli, R., Dagréou, S., Lapp, A., Billon, L. \& Peyrelasse, J. Nanostructure and mechanical properties of polybutylacrylate filled with grafted silica particles. Langmuir 22, 6683-6689 (2006).

15 Tertykh, V., Yanishpolskii, V. \& Bol'bukh, Y. Synthesis and characterization of functional chemically modified silica fillers. Macromol. Symp. 194, 141-146 (2003).

16 Oberdisse, J., El, H. A., Carrot, G., Jesitin, J. \& Boue, F. Structure and rheological properties of soft-hard nanocomposites: influence of aggregation and interfacial modification. Polymer 46, 6695-6705 (2005).

17 Jouault, N., Vallat, P., Dalmas, F., Said, S., Jestin, J. \& Boué, F. Well-dispersed fractal aggregates as filler in polymer-silica nanocomposites: long-range effects in rheology. Macromolecules 42, 2031-2040 (2009).
18 Park, S. J., Jin, S. Y. \& Kaang, S. Influence of thermal treatment of nano-scaled silica on interfacial adesion properties of the silica/rubber compounding. Mate. Sci. Eng. A 398, 137-141 (2005).

19 Nah, C., Huh, M. Y., Rhee, M. J. \& Yoon, T. H. Plasma surface modification of silica and its effect of properties of styrene-butadiene rubber compound. Polym. Int. 51, 510-518 (2002).

20 Mathew, G., Huh, M. Y., Rhee, J. M., Lee, M. H. \& Nah, C. Improvement of properties of silica-filled styrene-butadiene rubber composites through plasma surface modification of silica. Polym. Adv. Technol. 15, 400-408 (2004).

21 Shanmugharaj, A. M. \& Bhowmick, A. K. Dynamic mechanical properties of styrenebutadiene rubber vulcanizate filled with electron beam modified surface-treated dualphase filler. J. Appl. Polym. Sci. 88, 2992-3004 (2003).

22 Mélé, P., Marceau, S., Brown, D., Puydt, Y. N. \& Albérola, D. Reinforcement effects in fractal-structure-filled rubber. Polymer 43, 5577-5586 (2002).

23 Leblanc, J. L. Elastomer-filler interactions and the rheology of filled rubber compounds. J. Appl. Polym. Sci. 78, 1541-1550 (2000).

24 Flory, P. J. \& Rehner, J. J. Statistical mechanics of cross-linked polymer networks. II. Swelling. Chem. Phys. 2, 521-526 (1943).

25 Flory, P. J. Statistical mechanics of swelling of network structures. J. Chem. Phys. 18, 108-111 (1950).

26 Tager, A. Physical Chemistry of Polymers, Cornell University Press: Ithaca, NY, 1953. pp. 463.

27 Guo, B. C., Chen, F., Lei, Y. D. \& Jia, D. M. Tubular clay composites with high strength and transparency. J. Macromol. Sci. B 49, 1-11 (2010).

28 Chen, Y. F., Bagnall, D. M., Koh, H. J., Park, K. T., Hiraga, K., Zhu, Z. Q. \& Yao, T. Plasma assisted molecular beam epitaxy of $\mathrm{ZnO}$ on c-plane sapphire: growth and characterization. J. Appl. Phys. 84, 3912-3918 (1998).

29 Guo, B. C., Chen, F., Lei, Y. D., Liu, X. L., Wan, J. J. \& Jia, D. M. Styrene-butadiene rubber/halloysite nanotubes nanocomposites modified by sorbic acid. Appl. Surf. Sci. 255, 7329-7336 (2009).

30 Li, L., Chan, C. M., Weng, L. T. Xiang M. L. \& Jiang, M. Specific interaction between poly(styrene-co-4-vinylphenol) and poly(styrene-co-4-vinylpyridine) studied by X-ray photoelectron spectroscopy and time-of-flight secondary ion mass spectrometry. Macromolecules 31, 7248-7255 (1998).

$31 \mathrm{Li}$, L., Chan, C. M. \& Weng, L. T. Surface study of poly(styrene-co-4-vinylphenol) and poly(styrene-co-4-vinylpyridine) blends by XPS and TOF-SIMS. Polymer 39, 2355-2360 (1998).

32 Liu, S. Y., Chan, C. M., Weng, L. T. \& Jiang, M. Surface segregation in polymer blends and interpolymer complexes with increasing hydrogen bonding interactions. Polym. Sci. Part B Polym. Phys. 43, 1924-1930 (2005).

33 Choi, S. S. Influence of storage time and temperature and silane coupling agent on bound rubber formation in filled styrene-butadiene rubber compounds. Polym. Testing 21, 201-208 (2002).

34 Choi, S. S., Kim, I. S., Lee, S. G. \& Joo, C. W. Filler-polymer interactions of styrene and butadiene units in silica-filled styrene-butadiene rubber compounds. J. Polym. Sci. Part B Polym. Phys. 42, 577-584 (2004).

35 Wang, M. J. The role of filler networking in dynamic properties of filled rubber. Rubber Chem. Technol. 72, 430-448 (1999).

36 Castellano, M., Conzatti, L., Turrurro, A., Costa, G. \& Busca, G. Influence of the silane modifiers on the surface thermodynamic characteristics and dispersion of the silica into elastomer compounds. J. Phys. Chem. B 111, 4495-4502 (2007).

37 Waddell, W. H. \& Evans, L. R. Use of nonblack fillers in tire compounds. Rubber. Chem. Technol. 69, 377-423 (1996).

38 Sato, K lonic crosslinking of carboxylated SBR. Rubber Chem. Technol. 56, 942-958 (1983).

39 Treloar, L. R. G. The Physics of Rubber Elasticity, Clarendon Press: Oxford, 1975. 